\title{
Dielectric spectroscopy of grape juice at microwave frequencies
}

\author{
Ravika Vijay ${ }^{1 *}$, Ritu Jain ${ }^{2}$, and Krishna S. Sharma ${ }^{2}$ \\ ${ }^{1}$ Department of Physics, Poornima Group of Institution, \\ ${ }^{2}$ Department of Physics, The IIS University, Jaipur-302020, India
}

Received November 1, 2014; accepted March 10, 2015

\begin{abstract}
A b s t r a c t. The complex permittivity of fresh juice of two cultivars of grapes, Sultania (green grapes) and Black Monukka (black grapes) was measured in terms of the dielectric constant and dielectric loss factor over the frequency range from 1 to $50 \mathrm{GHz}$ and at temperatures ranging from 30 to $60^{\circ} \mathrm{C}$, by using the PNA network analyzer model E8364C and open ended coaxial probe 85070 E. The Cole-Cole plots and dielectric constant vs. (angular frequency) dielectric loss factor and dielectric constant $v s$. dielectric loss factor/(angular frequency) regression lines at different temperatures were used in Debye approximation to predict relaxation frequency of molecules for the two cultivars of grapes in the low frequency and high frequency limits, respectively. It was observed that the acidic character of green grapes is responsible for the large amplitude vibrational peaks in dielectric loss factor - frequency curves, in the high frequency region at higher temperatures. On the other hand, excess of sugar in black grapes suppresses the activity of water molecules, thereby suppressing the vibrational peaks at higher frequencies. Different relaxation frequencies found for the two cultivars of grapes suggest that they have different molecular structure.

K e y w o r d s: dielectric constant, dielectric loss factor, relaxation frequency, temperature, grapes
\end{abstract}

\section{INTRODUCTION}

The dielectric properties of materials serve as a measure of interaction of these materials with electromagnetic radiation and provide useful information about their molecular behaviour. Non-destructive testing techniques have been successfully used in agriculture and food industry (Jha et al., 2001). Such techniques are helpful to producers, handlers and processors for non-destructive determination of moisture, quality and other related characteristics of agricultural products and food items, and also for maturity and quality sensing in fresh fruits and vegetables (Nelson et al., 2006).

\footnotetext{
*Corresponding author e-mail: ravikavijay@gmail.com
}

Food materials essentially contain water, in small amounts in materials like food grains and in large amounts in materials like fruits and vegetables. The water molecules are polar in nature and hence contribute substantially to the polarisation of food molecules when placed in an alternating electric field. The dielectric properties of food materials are therefore those electrical properties which are responsible for the polarization of food molecules and measure the interaction of food with electromagnetic fields (Ahmed et al., 2007). Dielectric spectroscopy, which describes the dielectric properties of a sample as a function of frequency, has been successfully used for examining the behaviour of materials in radio and microwave frequency regions of electromagnetic spectrum (Skierucha et al., 2012). Electrical properties of food materials are finding increasing application in agriculture and food processing industries (Jha et al., 2011), as they are important in processes like moisture measurement in crops, protection of seeds and destruction of insects in fruits and nuts by selective heating on one hand and in processing of foods using microwave heating and for finding better processing conditions leading to better quality of foods on the other (Barbosa-Canovas et al., 2006).

Interaction of electromagnetic waves with an agro or food product is governed by its relative complex permittivity $\left(\varepsilon^{*}=\varepsilon^{\prime}-j \varepsilon^{\prime \prime}\right)$ where $j=\sqrt{ }-1$ is an imaginary unit. The real component of the complex permittivity (dielectric constant, $\left.\varepsilon^{\prime}\right)$ is related to the capacity of the material for energy storage, and the imaginary component (loss factor, $\left.\varepsilon^{\prime \prime}\right)$ to the energy dissipation in the dielectric medium.

The dependence of dielectric properties of several types of fruits and vegetables on temperature and frequency has been investigated by Feng et al. (2002), Guan et al. (2004), Ikediala et al. (2000) and Wang et al. (2003). Calay et al.

(C) 2015 Institute of Agrophysics, Polish Academy of Sciences 
(1995) observed that the dielectric constant of fruits increases with temperature, whereas the loss factor may either increase or decrease with increasing temperature, depending on the operating frequency; at higher frequencies the loss factor generally increases with increasing temperature (Nelson, 2003; Sosa-Morales et al., 2009).

Dielectric properties of the juices of several types of fruits, viz., apple, pear, orange, grapes and pineapple were studied in the frequency range from 20 to $4500 \mathrm{MHz}$ at temperatures from 15 to $95^{\circ} \mathrm{C}$ by Zhu et al. (2012). They observed that in all cases $\varepsilon^{\prime}$ decreased consistently with increasing frequency and it showed an almost linear increase with increasing temperature. Dielectric properties of a commercial apple juice product were also measured over the frequency range from $200 \mathrm{MHz}$ to $20 \mathrm{GHz}$ by Nelson and Bartley (2002). They reported that the influence of liquid water, which has a relaxation frequency of $19.2 \mathrm{GHz}$ at $25^{\circ} \mathrm{C}$, is clearly evident in the dielectric properties of apple juice and as the temperature increases, the relaxation frequency shifts to higher frequencies.

The dielectric properties of grapes were measured by Tulasidas et al. (1995) at a fixed frequency of $2.45 \mathrm{GHz}$ and moisture content varying from 80 to $15 \%$ (wet basis) at temperatures ranging from 25 to $80^{\circ} \mathrm{C}$, by using the open ended coaxial transmission line technique. They observed that both the dielectric constant $\left(\varepsilon^{\prime}\right)$ and the loss factor $\left(\varepsilon^{\prime \prime}\right)$ decreased with decreasing moisture content. Garcia et al. (2004) reported the dielectric properties of grape juice at 0.2 and $3 \mathrm{GHz}$ by using the same technique that was used by Tulasidas et al. (1995) and the dielectric properties of grape marc were measured by Solyorn et al. (2013) using the resonant cavity method. It was observed by them that at higher moisture contents the values of dielectric constant and loss factor show an increasing tendency, while temperature does not have a definite effect on them. Liu and Liu (2012) studied the effect of postharvest dehydration on dielectric properties of grapes during cold storage. Their results show that postharvest dehydration is a more effective way of preserving the quality of grapes during the period they are in cold storage.

However, reliable dielectric data on the dielectric properties of different cultivars of grapes over a wide range of frequencies, particularly above $20 \mathrm{GHz}$, are not yet available in literature. Most of the studies reporting on the dielectric properties of juices of fruits and vegetables are at frequencies lower than $20 \mathrm{GHz}$. Since the relaxation frequencies of molecules in water have been reported to lie at frequencies beyond $20 \mathrm{GHz}$ as well as at temperatures above $30^{\circ} \mathrm{C}$, and since water is the major component in all the juices, useful information regarding dielectric behaviour of juices may be expected at frequencies above $20 \mathrm{GHz}$ and temperatures above $30^{\circ} \mathrm{C}$ (Hasted, 1973). As such, in the present research, dielectric constant and loss factor of grapes juice in the frequency range 1 to $50 \mathrm{GHz}$ and temperatures $30^{\circ} \mathrm{C}$ and above were measured by using the coaxial probe system (85070E) with PNA Network Analyser (E8364C).

\section{MATERIAL AND METHOD}

Fresh samples of two cultivars of grapes Sultania (green grapes) and Black Monukka (black grapes), for the present research were obtained from the local supermarket. For experimental study, juice of the two cultivars was extracted by using a juicer and filtered by using fine grain filter paper. The dielectric constant $\left(\varepsilon^{\prime}\right)$ and loss factor $\left(\varepsilon^{\prime \prime}\right)$ of fresh juice of the two cultivars of grapes were measured by using a PNA network analyzer, model Agilent $\mathrm{E} 8364 \mathrm{C}$, in the frequency range from 1 to $50 \mathrm{GHz}$. The test probe consisted of an open ended coaxial probe system (Agilent 85070E). The system software calculates the dielectric parameters from the phase and amplitude of the signal reflected at the interface between the open-ended coaxial line and the sample to be analyzed. The instrument was calibrated by using three different loads:

- air,

- a short circuit with the metal contacts,

- pure water at room temperature.

The calibration curve for water is given in Fig.1, showing variation of $\varepsilon^{\prime}$ and $\varepsilon^{\prime \prime}$ with frequency (in the frequency range of $1-50 \mathrm{GHz})$ at room temperature $\left(20^{\circ} \mathrm{C}\right)$. After calibration, the instrument was tested by taking measurements on a standard liquid (methanol, in the present case) of known dielectric properties. The measured values of $\varepsilon^{\prime}$ and $\varepsilon^{\prime \prime}$ for methanol at frequencies from 1 to $50 \mathrm{GHz}$ at room temperature $\left(20^{\circ} \mathrm{C}\right)$ are displayed in Fig. 2, along with standard dielectric data (up to $5 \mathrm{GHz}$ ) reported by National Physical Laboratory, Delhi (Gregory and Clarke, 2012) and the values reported by Misra et al. (1990) up to $20 \mathrm{GHz}$. The values of dielectric parameters above $20 \mathrm{GHz}$ are not available in literature for a meaningful comparison. The agreement of the measured values of $\varepsilon^{\prime}$ and $\varepsilon^{\prime \prime}$ with the standard data for methanol and the values reported by

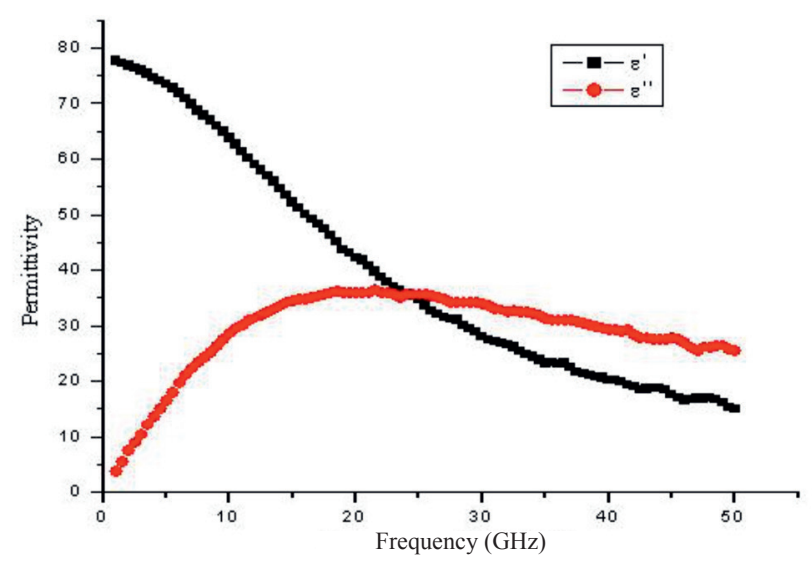

Fig. 1. Variation of dielectric constant $\left(\varepsilon^{\prime}\right)$ and loss factor $\left(\varepsilon^{\prime \prime}\right)$ of water with frequency at room temperature $\left(20^{\circ} \mathrm{C}\right)$. 


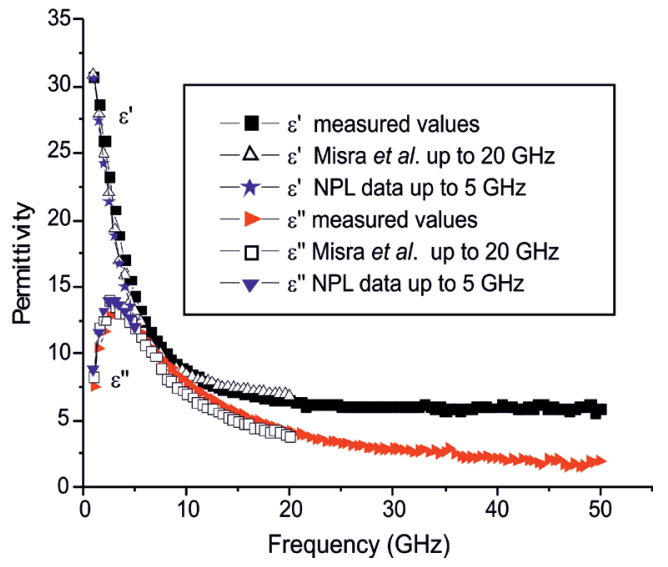

Fig. 2. Variation of dielectric constant $\left(\varepsilon^{\prime}\right)$ and loss factor $\left(\varepsilon^{\prime \prime}\right)$ of methanol with frequency at room temperature $\left(20^{\circ} \mathrm{C}\right)$ along with standard data for comparison.

Misra et al. (1990) confirms the accuracy of measurements. Sample temperature control was provided by circulating cold/hot water through the jacket surrounding the sample cup from a Haake B3 Constant Temperature water circulator with a digital control module. Observations were repeated three times for each sample at each temperature (from 30 to $60^{\circ} \mathrm{C}$ ) and for all the frequencies (from 1 to $50 \mathrm{GHz}$ ), so as to ensure consistency of the experimental data.

The Debye equatio $\mathrm{n}$ describes the dielectric response of a sample with a single relaxation time to the electromagnetic field and given by:

$$
\varepsilon=\varepsilon_{\infty}+\frac{\varepsilon_{s}-\varepsilon_{\infty}}{1+j \omega \tau},
$$

where: $\varepsilon_{\infty}$ is the dielectric constant at frequencies much higher than the relaxation frequency, $f_{r}=1 /(2 \pi \tau)$, at which the polar molecules do not have time to contribute to the polarization, $\varepsilon_{s}$ is the static dielectric constant, and $\tau$ is the relaxation time which is usually determined by experiment. From Eq. (1), the dielectric constant $\left(\varepsilon^{\prime}\right)$ and loss factor $\left(\varepsilon^{\prime \prime}\right)$ for a single relaxation time $(\tau)$ can be written as:

$$
\begin{gathered}
\varepsilon^{\prime}=\varepsilon_{\infty}+\frac{\varepsilon_{s}-\varepsilon_{\infty}}{1+\omega^{2} \tau^{2}}, \\
\varepsilon^{\prime \prime}=\left(\varepsilon_{s}-\varepsilon_{\infty}\right) \frac{\omega \tau}{1+\omega^{2} \tau^{2}} .
\end{gathered}
$$

The relaxation behaviour in many materials, such as biological samples, fruits and vegetables, is quite complex and hence several relaxation times are possible (Dias, 1996). At frequencies very low and very high with respect to the frequency of the molecular relaxation process the dielectric constant has constant values designated by $\varepsilon_{s}$ and $\varepsilon_{\infty}$, respectively.

The following three representations (Cole, 1955; Cole and Cole, 1941) which can be obtained from Eqs (2) and (3) represent the dielectric behaviour of the substance:
Cole-Cole plot: $\left(\varepsilon^{\prime}-\frac{\varepsilon_{s}-\varepsilon_{\infty}}{2}\right)^{2}+\varepsilon^{\prime \prime 2}=\left(\frac{\varepsilon_{s}-\varepsilon_{\infty}}{2}\right)^{2}$,

$\varepsilon^{\prime} v s .\left(\omega \varepsilon^{\prime \prime}\right)$ line: $\quad \varepsilon^{\prime}=\varepsilon_{s}-\tau\left(\omega \varepsilon^{\prime \prime}\right)$,

$\varepsilon^{\prime} v s .\left(\varepsilon^{\prime \prime} / \omega\right)$ line: $\quad \varepsilon^{\prime}=\varepsilon_{\infty}+\frac{1}{\tau} \frac{\varepsilon^{\prime \prime}}{\omega}$.

Whereas the Cole-Cole plot for a material obeying Debye relation is of semicircular form, linear regression plots of Eqs (5) and (6) can be used to find out relaxation time $(\tau)$ and hence relaxation frequency $\left(f_{r}\right)$. The relaxation frequencies obtained from Eqs (5) and (6) have been designated as $f_{r 1}$ and $f_{r 2}$ respectively in this work. The relevant relaxation times are symbolized respectively by $\tau_{1}$ and $\tau_{2}$.

\section{RESULTS AND DISCUSSION}

The permittivity data for the two cultivars of grapes (Sultania and Black Monukka), as obtained from the present work, are presented in Figs 3-6. In Fig. 3a, the variation of $\varepsilon^{\prime}$ with frequency is shown for the temperatures (30 to $60^{\circ} \mathrm{C}$ ) over the frequency range from 1 to $50 \mathrm{GHz}$ for fresh juice of green grapes (Sultania). It is observed that $\varepsilon^{\prime}$ decreases continuously with increasing frequency at all temperatures, except for $60^{\circ} \mathrm{C}$. At $60^{\circ} \mathrm{C}$ the value of $\varepsilon^{\prime}$ decreases with frequency up to $15 \mathrm{GHz}$ and then remains

a

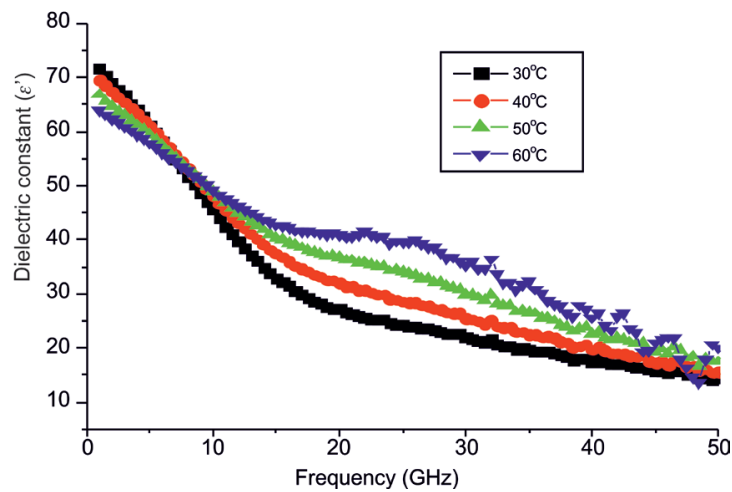

$\mathrm{b}$

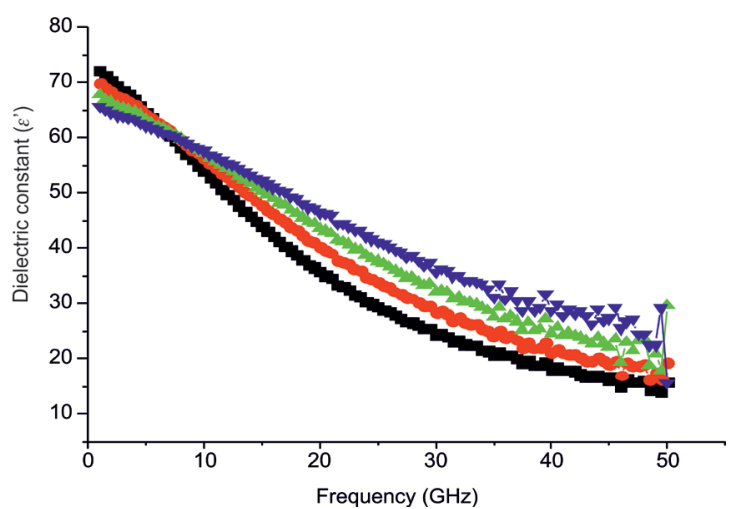

Fig. 3. Frequency dependence of dielectric constant $\left(\varepsilon^{\prime}\right)$ of: $\mathrm{a}$ - green grapes (Sultania), b - black grapes (Black Monukka) at indicated temperatures. 
almost uniform up to $19 \mathrm{GHz}$, and thereafter it shows fluctuations in the form of small vibrational peaks. A slow decrease in the average value of $\varepsilon^{\prime}$ is also noticed beyond $30 \mathrm{GHz}$. It is also observed that at 30 and $40^{\circ} \mathrm{C}$, the $\varepsilon^{\prime}-\mathrm{f}$ curves intersect each other at about $5 \mathrm{GHz}$, while the curves for 50 and $60^{\circ} \mathrm{C}$ intersect at about $10 \mathrm{GHz}$. Thus, the $\varepsilon^{\prime}-\mathrm{f}$ curves for different temperatures intersect each other somewhere in the frequency region $(5 \mathrm{GHz} \leq f \leq 10 \mathrm{GHz})$. These curves show dielectric dispersion with respect to this intersection frequency region. Below this frequency region $(f<$ $5 \mathrm{GHz}) \varepsilon^{\prime}$ decreases with increasing temperature whereas above this frequency region $(f>10 \mathrm{GHz}) \varepsilon^{\prime}$ increases with increasing temperature due to the effect of relaxation frequency. The appearance of small vibrational peaks and the general behaviour of $\varepsilon^{\prime}$ at higher temperatures $\left(50\right.$ and $\left.60^{\circ} \mathrm{C}\right)$ and higher frequencies $(f>30 \mathrm{GHz})$ may be attributed to the fact that in grape juice carbohydrate (dissolved sugars) are the main MW susceptors which reduce the water activity at higher temperatures and higher frequencies (Mudgett, 1986). In materials containing sugars, free water is influenced by the hydroxyl groups of the sugars, and therefore the hydrogen bonds are stabilised, giving rise to small amplitude peaks at the vibrational frequencies of such bonds, as observed by Tulasidas et al. (1995) for grapes.

In Fig. 3b, the variation of $\varepsilon^{\prime}$ for black grapes (Black Monukka) with frequency is shown at different temperatues $\left(30-60^{\circ} \mathrm{C}\right)$. The general behaviour of the curves for black grapes is similar to that of green grapes. At higher temperatures and higher frequencies, behaviour similar to that observed in green grapes is also observed in black grapes, however for black grapes the $\varepsilon^{\prime}-f$ curves are comparatively smoother and vary more systematically with frequency as compared to green grapes at all temperatures. At 30 and $40^{\circ} \mathrm{C}, \varepsilon^{\prime}$-f curves intersect each other at about $5.5 \mathrm{GHz}$, while as at 50 and $60^{\circ} \mathrm{C}$ these curves intersect near $9.5 \mathrm{GHz}$. Thus, the $\varepsilon^{\prime}-f$ curves for different temperatures intersect each other somewhere in the frequency region $(5.5 \mathrm{GHz} \leq f \leq$ $9.5 \mathrm{GHz}$ ). These curves show dielectric dispersion with respect to this intersection frequency region. Below this frequency region $(f<5.5 \mathrm{GHz}) \varepsilon$ ' decreases with increasing temperature whereas above this frequency region $(f>$ $9.5 \mathrm{GHz}) \varepsilon^{\prime}$ increases with increase in temperature, which may be attributed to the effect of relaxation frequency, lying in this frequency region. The shorter intersection frequency region less pronounced vibrational peaks suggest that in black grapes carbohydrates (sugars) play a more dominant role over water molecules, as compared to green grapes.

In Fig. 4, the variation of $\varepsilon^{\prime \prime}$ with frequency is shown for temperatures $\left(30\right.$ to $\left.60^{\circ} \mathrm{C}\right)$ over the frequency range from 1 to $50 \mathrm{GHz}$ for fresh juice of green grapes (Sultania). It is observed that at low temperatures $\left(30\right.$ and $\left.40^{\circ} \mathrm{C}\right), \varepsilon^{\prime \prime}$ of green grapes increases with increasing frequency, reaches its maximum value at about $10 \mathrm{GHz}$ for $30^{\circ} \mathrm{C}$ and $12 \mathrm{GHz}$ at $40^{\circ} \mathrm{C}$, and then decreases with increasing frequency and shows small amplitude vibrational peaks between 45 and

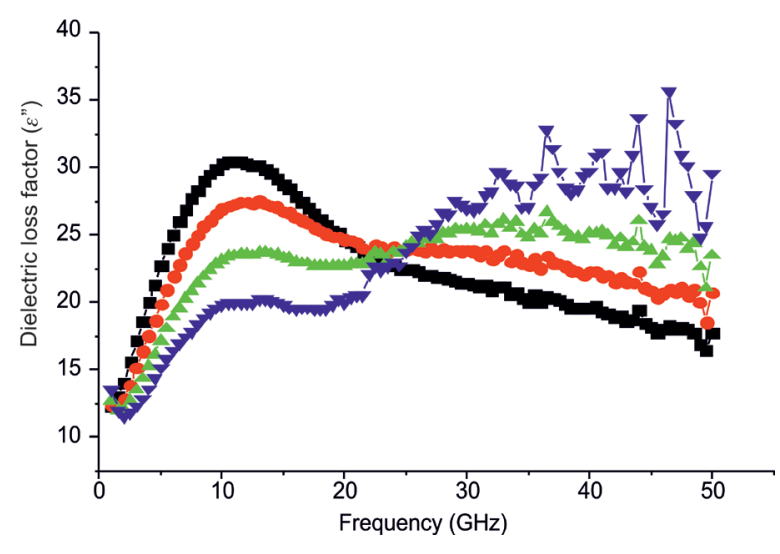

Fig. 4. Frequency dependence of dielectric loss factor $\left(\varepsilon^{\prime \prime}\right)$ of green grapes (Sultania) at indicated temperatures. Legend as in Fig. 3.

$50 \mathrm{GHz}$. At higher temperatures $\left(50\right.$ and $\left.60^{\circ} \mathrm{C}\right), \varepsilon^{\prime \prime}$ shows a somewhat different behaviour, ie it increases with increasing frequency till it acquires a maximum value (at about $12 \mathrm{GHz}$ ), then it decreases and shows a shallow dip at about $16 \mathrm{GHz}$ for both temperatures. Thereafter $\varepsilon^{\prime \prime}$ increases and acquires almost a uniform average value and shows small amplitude vibrational peaks at $50^{\circ} \mathrm{C}$, whereas large amplitude vibrational peaks are obtained at $60^{\circ} \mathrm{C}$ in the frequency range of $30-50 \mathrm{GHz}$. The $\varepsilon "-f$ curves for all the temperatures cross each other at about $22 \mathrm{GHz}$. The peak value obtained in $\varepsilon^{\prime \prime}-f$ curves for $30^{\circ} \mathrm{C}$ temperature at about $10 \mathrm{GHz}$ shifts to about $12 \mathrm{GHz}$ at higher temperatures $\left(40-60^{\circ} \mathrm{C}\right)$, which may be considered to be due to a decrease in relaxation time with increase in temperature. The same value of peak frequency at temperatures of 40 to $60^{\circ} \mathrm{C}$ suggests that the relaxation time does not change much in this temperature range. In the lower frequency range, however, a different feature is observed in $\varepsilon^{\prime \prime}-\mathrm{f}$ curves, ie at higher temperatures $\left(50-60^{\circ} \mathrm{C}\right) \varepsilon^{\prime \prime}$ of green grape juice first decreases and then increases with increasing frequency and a valley type structure is obtained near $1.5 \mathrm{GHz}$ at $50^{\circ} \mathrm{C}$ and $2 \mathrm{GHz}$ at $60^{\circ} \mathrm{C}$ (Fig. 5), which may be due to the acidic nature of green grape juice, acid ions playing a dominant role in this frequency region at higher temperatures. Increase in ionisation with rise in temperature may lead to an increase in acidic component of grape juice. This results in an increase in dielectric loss with increase in temperature (Mudgett et al., 1980). The large amplitude peaks obtained in $\varepsilon^{\prime \prime}-\mathrm{f}$ curves at higher temperatures $\left(50-60^{\circ} \mathrm{C}\right)$ and higher frequencies $(30-50 \mathrm{GHz})$ may be considered to be the relaxation loss peaks which may arise due to molecular stretching and molecular liberations.

In Fig. 6, the variation of $\varepsilon^{\prime \prime}$ for black grapes (Black Monukka) with frequency is shown at different temperatures $\left(30-60^{\circ} \mathrm{C}\right)$. It is observed that $\varepsilon^{\prime \prime}$ increases with frequency at all the temperatures up to $25 \mathrm{GHz}$, where the $\varepsilon^{\prime \prime}$-f curves at these temperatures cross each other. It is observed that at 30 and $40^{\circ} \mathrm{C}, \varepsilon^{\prime \prime}$ increases with frequency 


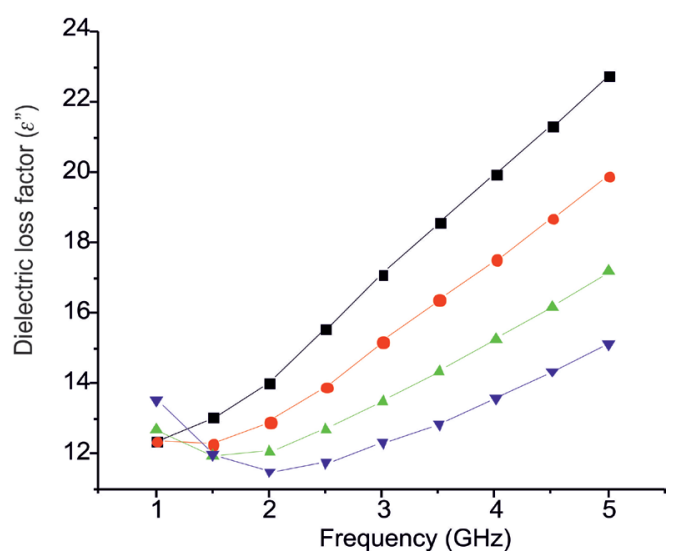

Fig. 5. Enlarged view of frequency dependence (1-5 GHz) of dielectric loss factor $\left(\varepsilon^{\prime \prime}\right)$ of green grapes (Sultania) at indicated temperatures. Legend as in Fig. 3.

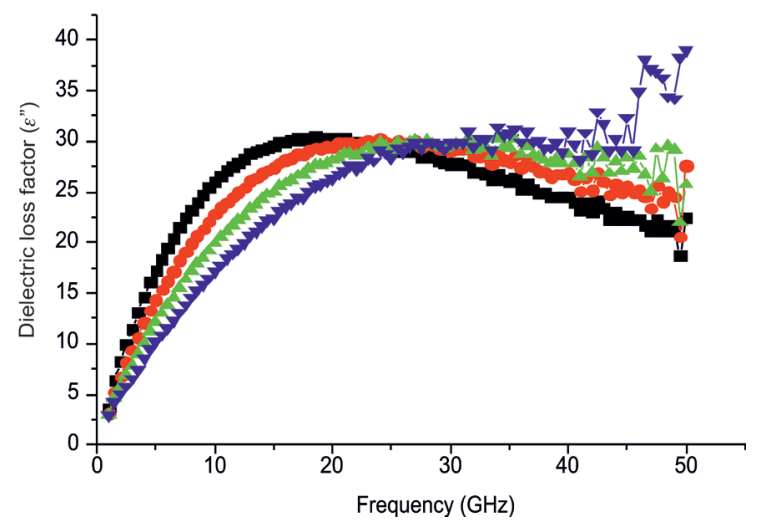

Fig. 6. Frequency dependence of dielectric loss factor $\left(\varepsilon^{\prime \prime}\right)$ of black grapes (Black Monukka) at indicated temperatures. Legend as in Fig. 3. and acquires a maximum value at about $18 \mathrm{GHz}$ for $30^{\circ} \mathrm{C}$ and at about $22 \mathrm{GHz}$ for $40^{\circ} \mathrm{C}$, thereafter $\varepsilon^{\prime \prime}$ decreases with increase in frequency and in the higher frequency region $(f>40 \mathrm{GHz})$ small vibrational peaks are obtained. It is observed that below $25 \mathrm{GHz} \varepsilon^{\prime \prime}$ decreases as we increase the temperature, whereas above $25 \mathrm{GHz}$ a reverse trend is observed, ie $\varepsilon^{\prime \prime}$ increases with increasing temperature. At higher temperatures $\left(50\right.$ and $\left.60^{\circ} \mathrm{C}\right), \varepsilon^{\prime \prime}$ after acquiring a maximum value at about $25 \mathrm{GHz}$ shows an almost uniform average value at $50^{\circ} \mathrm{C}$, but increases further with frequency at $60^{\circ} \mathrm{C}$. Vibrational peaks of higher magnitudes are also observed at 50 and $60^{\circ} \mathrm{C}$ at frequencies above $30 \mathrm{GHz}$, which may be considered to arise due to relaxation losses. The absence of valley formation for black grapes in the low frequency region suggests the absence of acids in black grapes as compared to green grapes.

The present values of $\varepsilon^{\prime}$ and $\varepsilon^{\prime \prime}$ for green grapes and black grapes at $2.5 \mathrm{GHz}$ and temperatures of 30 to $60^{\circ} \mathrm{C}$ are displayed in Table 1 along with the values of $\varepsilon^{\prime}$ and $\varepsilon^{\prime \prime}$ at frequency $2.45 \mathrm{GHz}$ for the pulp of seedless Thomson grapes reported by Tulasidas et al. (1995) at corresponding temperatures, for the sake of comparison. It may be observed from the Table that the present values of $\varepsilon^{\prime}$ for the two cultivars at all the temperatures are in good agreement with the values reported by Tulasidas et al. (1995). However, the present values of loss factor $\left(\varepsilon^{\prime \prime}\right)$ for black grapes at all the temperatures are observed to be lower than the $\varepsilon^{\prime \prime}$ values of green grapes and the values reported by Tulasidas et al. (1995) for Thompson seedless grapes. This may be accounted for by the presence of excess sugar in black grapes, the sugar molecules suppressing the activity of water molecules.

T a b l e 1. Dielectric parameters of grapes at different temperatures (at $2.5 \mathrm{GHz}$ )

\begin{tabular}{|c|c|c|c|c|c|c|c|c|c|}
\hline \multirow{4}{*}{ No. } & \multirow{4}{*}{ Sample } & \multicolumn{8}{|c|}{ Temperature $\left({ }^{\circ} \mathrm{C}\right)$} \\
\hline & & \multicolumn{2}{|c|}{30} & \multicolumn{2}{|c|}{40} & \multicolumn{2}{|c|}{50} & \multicolumn{2}{|c|}{60} \\
\hline & & \multicolumn{8}{|c|}{ Dielectric parameter } \\
\hline & & $\varepsilon^{\prime}$ & $\varepsilon^{\prime \prime}$ & $\varepsilon^{\prime}$ & $\varepsilon^{\prime \prime}$ & $\varepsilon^{\prime}$ & $\varepsilon^{\prime \prime}$ & $\varepsilon^{\prime}$ & $\varepsilon^{\prime \prime}$ \\
\hline 1 & $\begin{array}{l}\text { Green grapes } \\
\text { (Sultania) (juice) }\end{array}$ & 67.93 & 15.55 & 66.42 & 13.89 & 63.84 & 12.69 & 61.55 & 11.73 \\
\hline 2 & $\begin{array}{l}\text { Black grapes } \\
\text { (Black Monukka) } \\
\text { (juice) }\end{array}$ & 63.98 & 5.87 & 67.61 & 8.21 & 65.79 & 6.98 & 63.98 & 5.87 \\
\hline 3 & $\begin{array}{l}\text { Thompson } \\
\text { seedless grape } \\
\text { (pulp) } \\
\text { Tulasidas et al. } \\
\text { (1995) }\end{array}$ & 68 & 17 & 66 & 15 & 63 & 14 & 58 & 13 \\
\hline
\end{tabular}


Green grapes
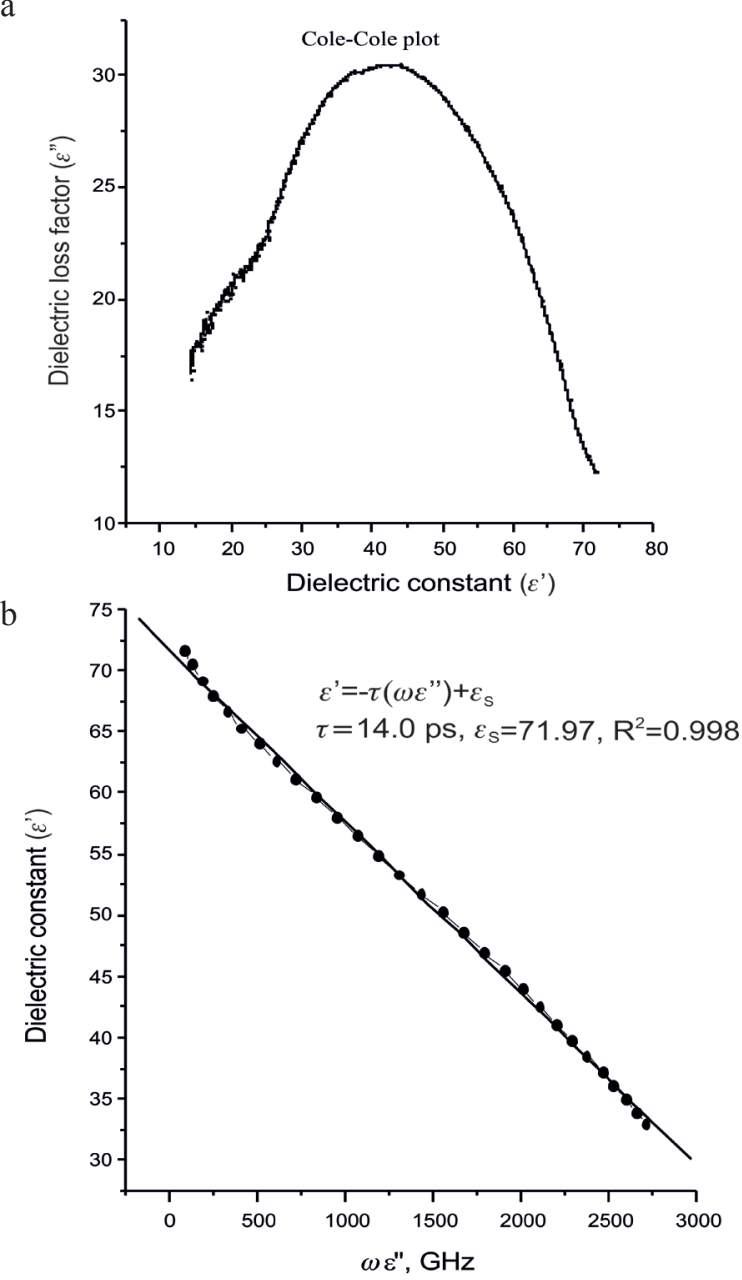

c

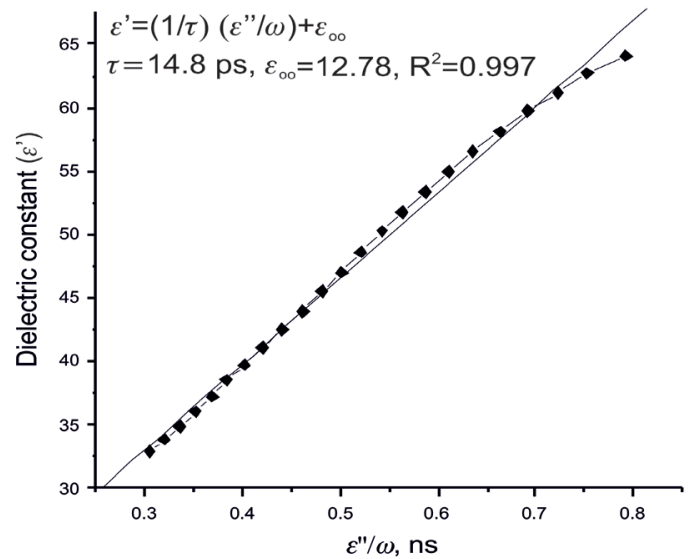

Black grapes
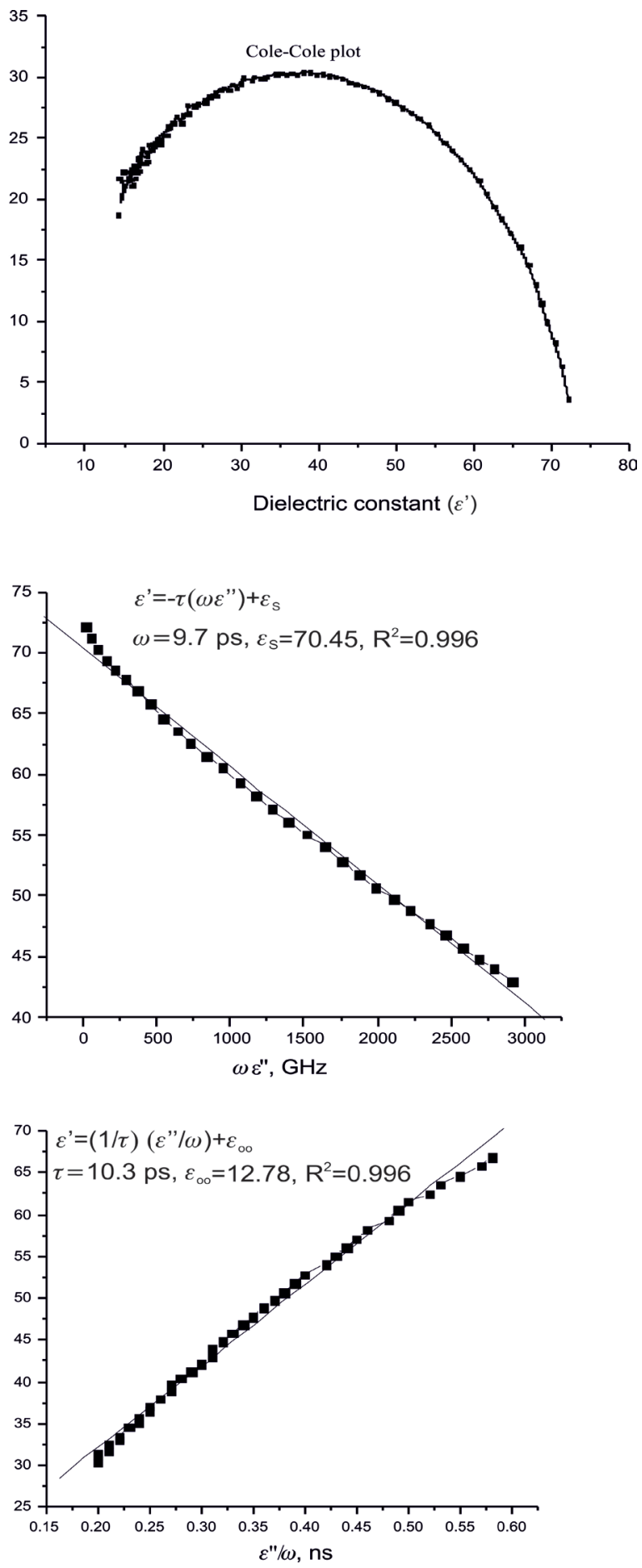

Fig. 7. Cole-Cole plot (a), $\varepsilon$ 'vs. $\omega \varepsilon "$ line (b) and $\varepsilon^{\prime}$ vs. $\varepsilon " / \omega$ line (c) for green and black grapes at $30^{\circ} \mathrm{C}$. 
T a b l e 2. Dielectric relaxation parameters estimated from permittivity measurements between 1 to $50 \mathrm{GHz}$ of fresh juice of green and black grapes at temperatures from 30 to $60^{\circ} \mathrm{C}$

\begin{tabular}{|c|c|c|c|c|c|c|c|c|}
\hline \multirow{3}{*}{$\begin{array}{l}\text { Temperature } \\
\left({ }^{\circ} \mathrm{C}\right)\end{array}$} & \multicolumn{8}{|c|}{ Relaxation parameters from linear regression } \\
\hline & \multicolumn{4}{|c|}{ Estimates from $\varepsilon^{\prime} v s . \omega \varepsilon^{\prime \prime}$ line } & \multicolumn{4}{|c|}{ Estimates from $\varepsilon^{\prime} v s . \varepsilon^{\prime \prime} / \omega$ line } \\
\hline & $\begin{array}{c}\tau_{1} \\
(\mathrm{ps})\end{array}$ & $\begin{array}{c}f_{r 1} \\
(\mathrm{GHz})\end{array}$ & $\varepsilon_{\mathrm{S}}$ & $\mathrm{R}^{2}$ & $\begin{array}{c}\tau_{2} \\
(\mathrm{ps})\end{array}$ & $f_{r 2}$ & $\varepsilon_{\infty}$ & $\mathrm{R}^{2}$ \\
\hline \multicolumn{9}{|c|}{ Green grapes } \\
\hline 30 & 14.0 & 11.30 & 71.97 & 0.998 & 14.8 & 10.75 & 14.32 & 0.995 \\
\hline 40 & 11.0 & 14.40 & 67.99 & 0.988 & 14.7 & 10.83 & 18.60 & 0.999 \\
\hline 50 & 10.0 & 15.90 & 66.22 & 0.997 & 18.5 & 8.5 & 25.27 & 0.992 \\
\hline 60 & 11.0 & 14.40 & 63.57 & 0.996 & 18.1 & 8.7 & 31.69 & 0.984 \\
\hline \multicolumn{9}{|c|}{ Black grapes } \\
\hline 30 & 9.7 & 16.41 & 70.45 & 0.993 & 10.3 & 15.45 & 12.78 & 0.996 \\
\hline 40 & 8.0 & 19.90 & 68.41 & 0.992 & 9.2 & 17.21 & 16.06 & 0.987 \\
\hline 50 & 7.0 & 22.74 & 66.39 & 0.990 & 8.2 & 19.34 & 17.79 & 0.981 \\
\hline 60 & 6.0 & 26.53 & 64.42 & 0.995 & 8.8 & 17.92 & 26.26 & 0.965 \\
\hline
\end{tabular}

The Cole-Cole plot and the linear regression lines for $\varepsilon^{\prime} v s$. $\omega \varepsilon^{\prime \prime}$ plot and $\varepsilon^{\prime} v s . \varepsilon^{\prime \prime} / \omega$ plot for green and black grapes are shown in Fig. 7. Similar plots can be made for other temperatures. It can be observed from these diagrams that the Cole-Cole plot for black grapes is closer to the semicircular form predicted by the Debye theory. The deformation obtained for green grapes may be accounted for by its acidic character. From the $\varepsilon^{\prime}$ vs. $\omega \varepsilon^{\prime \prime}$ plots the relaxation time ( $\tau_{1}$ in ps), relaxation frequency $\left(f r_{1}\right.$ in $\left.\mathrm{GHz}\right)$ and static dielectric permittivity $\varepsilon_{\mathrm{s}}$ can be obtained. The relevant values for green grapes at temperatures of 30 to $60^{\circ} \mathrm{C}$ are shown on the left hand side in Table 2 which also contains $\mathrm{R}^{2}$ values showing deviations from the straight line character. Similarly, from $\varepsilon^{\prime} v s . \varepsilon^{\prime \prime} / \omega$ plots we obtain the relaxation time $\left(\tau_{2}\right.$ in ps), relaxation frequency $\left(f_{r 2}\right.$ in $\mathrm{GHz})$ and dielectric permittivity at optical frequencies $\left(\varepsilon_{\infty}\right)$, as displayed on the right hand side of Table 2, along with $\mathrm{R}^{2}$ values showing deviation from the straight line character. From Fig. 7 the relevant values of parameters like $\tau_{1}$, $f_{r 1}, \varepsilon_{\mathrm{s}}$ and $\mathrm{R}^{2}$ from $\varepsilon^{\prime} v s . \omega \varepsilon^{\prime \prime}$ regression line, and $\tau_{2}, f_{r 2}, \varepsilon_{\infty}$ and $\mathrm{R}^{2}$ from $\varepsilon^{\prime} v s . \varepsilon^{\prime \prime} / \omega$ regression line can be obtained for black grapes. The dielectric data for black grapes obtained as above are shown in Table 2.

It can be observed from Table 2 for green and black grapes that in both cases the values of $\tau$ and $f_{r}$ at any temperature, as observed from the two types of regression lines, are nearly equal. Whereas $\tau_{1}$ decreases with increasing temperature, $f_{r 1}$ increases with temperature and $\varepsilon_{\mathrm{s}}$ decreases with increasing temperature for both cultivars of grapes. On the other hand, whereas $\tau_{2}$ and $f_{r 2}$ do not show any definite trend with increasing temperature, $\varepsilon_{\infty}$ is observed to increase with increasing temperature for both cultivars. The Cole-Cole plot and the two regression lines show an excellent Debye-type behaviour. Further, since the $\varepsilon^{\prime} v s . \varepsilon^{\prime \prime} / \omega$ plots show large deviations from the straight line character below $2.45 \mathrm{GHz}$ (ie for large values of $\varepsilon^{\prime \prime} / \omega$ ) for both the cultivars, we do not take into account the values obtained below $3 \mathrm{GHz}$ in the $\varepsilon^{\prime} v s . \varepsilon^{\prime \prime} / \omega$ plots. Therefore, in the present analysis only the permittivity data above $3 \mathrm{GHz}$ is used. The anomalous behaviour below $5 \mathrm{GHz}$ may be considered to be due to the influence of ionic conduction at these frequencies.

\section{CONCLUSIONS}

1. The present work provides reliable data for the dielectric properties of the two cultivars of grapes at frequencies up to $50 \mathrm{GHz}$.

2. At low frequencies and high temperatures, the acid ions present in green grapes play a dominant role, thereby giving rise to valley type structures in dielectric loss factor-f curves. The acid ions are also responsible for large amplitude vibrational peaks at higher frequencies and higher temperatures.

3. The excess of sugar molecules present in black grapes not only suppress the valley type structure in dielectric loss factor-f curves obtained for green grapes, but the amplitude of vibrational peaks at higher frequencies and higher temperatures is also partially suppressed and therefore the dielectric losses for black grapes are lower as compared to green grapes. 
4. The relaxation frequencies for black grapes are found to be higher as compared to green grapes, indicating that relaxation time for sugar molecules is smaller as compared to acid ions or the complex molecules formed by them with the grape molecules.

5. As temperature is increased the relaxation time decreases and the relaxation frequency increases for both cultivars, showing that at higher temperatures the molecules acquire more energy and become more mobile to follow the changes in the electromagnetic field applied.

\section{REFERENCES}

Ahmed J., Ramaswamy H.S., and Raghavan V.G.S., 2007. Dielectric properties of Indian Basmati rice flour slurry. J. Food Eng., 80, 1125-1133.

Barbosa-Canovas G.V., Juliano P., and Peleg M., 2006. Engineering properties of foods. Food Engineering. In: Encyclopedia of Life Support Systems. (Ed. V.G. BarbosaCanovas). Developed under Auspices of the UNESCO, EOLSS Publishers. Oxford, UK.

Calay R.K., Newborough M., Probert D., and Calay P.S., 1995. Predictive equations for the dielectric properties of foods. Int. J. Food Sci. Technol., 29, 699-713.

Cole K.S. and Cole R.H., 1941. Dispersion and absorption in dielectrics. J. Chem. Phys., 9, 341-351.

Cole R.H., 1955. On the analysis of dielectric relaxation measurements. J. Chem. Phys., 23, 493-499.

Dias C.J., 1996. Determination of a distribution of relaxation frequencies based on experimental relaxational data. Am. Physical Society Physical Review, B, 53, 14212-14222.

Feng H., Tang J., and Cavalieri R.P., 2002. Dielectric properties of dehydrated apples as affected by moisture and temperature. Trans ASAE, 45, 129-135.

Garcia A., Torres J.L., De Blas M., De Francisco A. and Illanes R., 2004. Dielectric characteristics of grape juice and wine. Biosystems Eng., 88, 343-349.

Gregory A.P. and Clarke R.N., 2012. Tables of the complex permittivity of dielectric reference liquids at frequencies up to 5 GHz. NPL Report (CETM 33), Teddington, London, UK.

Guan D., Cheng M., Wang Y., and Tang J., 2004. Dielectric properties of mashed potatoes relevant to microwave and radio-frequency pasteurization and sterilization processes. J. Food Sci., 69, 30-37.

Hasted J.B., 1973. Aqueous dielectrics Series: Studies in Chemical Physics. Chapman and Hall Press, London, UK.

Ikediala J.N., Tang J., Drake S.R., and Neven L.G., 2000. Dielectric properties of apple cultivars and codling moth larvae. Trans ASAE, 43, 1175-1184.

Jha S.N., Matsuoka T., and Kawano S., 2001. A simple NIR instruments for liquid type samples. In: Proc. Annual Meeting of the Japanese Society of Agricultural Structures, September 4-5, Nihon University Shonan Campus, Fujisawa, Kanagawa, Japan.
Jha S.N., Narsaiah K., Basediya A.L., Sharma R., Jaiswal P., Kumar R., and Bhardwaj R., 2011. Measurement techniques and application of electrical properties for nondestructive quality evaluation of foods- a review. J. Food Sci. Technol., 48, 387-411.

Liu Y. and Liu X., 2012. Effect of postharvest dehydration on dielectric properties of grape during cold storage. Nongye Jixie Xuebao/Trans. Chinese Soc. Agric. Machinery, 43, 143-149.

Misra D., Chabbra M., Epstein Benjamin R., Mirotznik M., and Foster Kenneth R., 1990. Noninvasive Electrical Characterization of Materials at Microwave Frequencies Using an Open-Ended Coaxial Line: Test of an Improved Calibration Technique. IEEE Trans on Microwave Theory and Techniques, 38, 8-14.

Mudgett R.E., 1986. Electrical properties of foods. In: Engineering Properties of Foods (Eds M.A. Rao, S.S.H. Rizvi). Marcel Dekker, New York, USA.

Mudgett R.E., Goldblith S.A., Wang D.I.C. and Westphal W.B., 1980. Dielectric behavior of a semisolid food at low, intermediate and high moisture contents. J. Microw. Power., $15,27-36$.

Nelson S.O., 2003. Frequency- and temperature-dependent permittivities of fresh fruits and vegetables from 0.01 to 1.8 GHz. Trans. ASAE, 46, 567-574.

Nelson S.O. and Bartley P.G. Jr., 2002. Frequency and temperature dependence of dielectric properties of food materials. Trans. ASAE, 45, 1223-1227.

Nelson S.O., Trabelsi S., and Kays S.J., 2006. Dielectric spectroscopy of honeydew melons from $10 \mathrm{MHz}$ to $1.8 \mathrm{GHz}$ for quality sensing. Trans. ASABE, 49, 1977-1981.

Skierucha W., Wilczek A., and Szypłowska A., 2012. Dielectric spectroscopy in agrophysics. Int. Agrophys., 26, 187-197.

Solyorn K., Kraus S., Mato R.B., Gaukel V., Schuchmann H.P., and Cocero M.J., 2013. Dielectric properties of grape marc: Effect of temperature, moisture content and sample preparation method. J. Food Eng., 119, 33-39.

Sosa-Morales M.E., Tiwari G., Wang S., Tang J., Garcia H.S., and Lopez-Malo A., 2009. Dielectric heating as a potential post-harvest treatment of disinfesting mangoes. Part I: Relation between dielectric properties and ripening. Biosystems Eng., 103, 297-303.

Tulsidas T.N., Raghavan G.S.V., van de Voort F., and Girard R., 1995. Dielectric properties of grapes and sugar solutions at 2.45 GHz. J. Microwave Power Electromagnetic Energy, 30, 117-123.

Wang Y., Wig T.D., Tang J., and Hallberg L.M., 2003. Dielectric properties of foods relevant to RF and microwave pasteurisation and sterilization. J. Food Eng., 57, 257-268.

Zhu X., Guo W., and Wu X., 2012. Frequency and temperature dependent dielectric properties of fruit juices associated with pasteurization by dielectric heating. J. Food Eng., 109, 258-266. 